\title{
Production and Utilization of SPIONs for In-vitro Drug Release and X-ray Imaging
}

\author{
Antony V. Samrot ${ }^{1 *}\left(\mathbb{D}\right.$, Saipriya C. ${ }^{2}$, Durga Sruthi P. ${ }^{2}$, A. Jenifer Selvarani ${ }^{2}$, Raji P. ${ }^{2}$, \\ Prakash P. ${ }^{2}$, Paulraj Ponnaiah ${ }^{1}$, Thirumurugan R. ${ }^{3}$, Sajeesh Pattammadath ${ }^{1}$, Sajna \\ Keeyari Purayil ${ }^{1}$, Pazhayakath Thevarkattil Mohamed Javad ${ }^{1}$ and lyappan P. ${ }^{1}$
}

${ }^{1}$ School of Biosciences, Faculty of Medicine, Bioscience and Nursing, MAHSA University, Jenjarom, Selangor - 42610, Malaysia. ${ }^{2}$ Department of Biotechnology, Sathyabama Institute of Science and Technology, Jeppiar Nagar, Chennai - 600 119, Tamil Nadu, India. ${ }^{3}$ Department of Transfusion Medicine, JIPMER, Puducherry - 605 006, India.

\begin{abstract}
In this study, SPIONs were produced in the presence of cobalt as catalyst. SPIONs formed by this chemical co-precipitation were size around $20 \mathrm{~nm}$. After producing the SPIONs, it was subjected for functionalization with oleic acid and loaded with drug - itraconazole (a drug possess antifungal and antibacterial activity) and encapsulated with polyhydroxybutyrate (PHB). The produced core-shell SPIONS was used for antimicrobial study against two bacteria namely - Pseudomonas aeruginosa and Brevibacillus brevis and a fungi - Candida albicans. It was found to be effectively releasing drug for more than 3 hours. The SPIONs alone was acting good as contrasting agent and used for enhancing $\mathrm{X}$-ray imaging.
\end{abstract}

Keywords: SPIONs, PHB, drug release, X-ray imaging

\footnotetext{
*Correspondence: antonysamrot@gmail.com

(Received: November 18, 2019; accepted: April 04, 2020)

Citation: Samrot AV, Saipriya C, Durga SP, et al. Production and Utilization of SPIONs for in-vitro Drug Release and X-ray Imaging. J Pure Appl Microbiol. 2020;14(2):1317-1322. doi: 10.22207/JPAM.14.2.27

(C) The Author(s) 2020. Open Access. This article is distributed under the terms of the Creative Commons Attribution 4.0 International License which permits unrestricted use, sharing, distribution, and reproduction in any medium, provided you give appropriate credit to the original author(s) and the source, provide a link to the Creative Commons license, and indicate if changes were made.
} 


\section{INTRODUCTION}

In this modern era metal based nanoparticles are being exploited in different fields including environmental remediation, processing of leather etc. ${ }^{1-7}$ Present days, metal based nanoparticles are used in biomedical applications for diagnosis and therapy. As a part of therapeutics, these particles used for targeted drug delivery could reduce the concentration of drug required and also enhance the potency of drug. Some metals are known to have side effects, but can be ruled out when proper nanoparticle is chosen as drug carrier, one such is SPIONs (superparamagnetic iron oxide nanoparticles), which is known for its biocompatibility, even it can modified to aid the tagging of any drug/ ligand / molecule/ protein and helps in targeted delivery to desired site ${ }^{8-11}$. These SPIONs can be moved or brought to target location by controlled external magnetic movement. SPIONs do have superparamagnetic property which do have various properties including high saturation field, extra anisotropy contributions or shifted loops after field cooling ${ }^{12}$. Sometimes these SPIONs' properties influence them to not to have magnetic property, this can be overruled by using proper functionalizing agent, these functionalization helps in adding desired molecules too. Reports are there for using these SPIONs in targeted drug delivery in vivo as well as invitro ${ }^{11-14}$. Moreover, these kind of SPIONs have been used to deliver antibiotics against bacteria ${ }^{8,10}$. Functionalization also gives stability to $\mathrm{it}^{11,15}$. Having understood the application and properties of SPIONs, this work to has been done to produce these SPIONs having Cobalt as one of catalyzing agent (to study it's influence in SPIONs formation), after production it was functionalized with oleic acid, followed with itraconazole coating and studied for its in vitro antibacterial activity. The produced naked SPIONs was utilized as contrasting agent for $\mathrm{X}$-ray imaging.

\section{MATERIALS AND METHODS}

\section{Chemical used}

All chemicals were bought from Qualigens, India and all are of analytical grade. Pure microbial fermentation product Poly hydroxy butyrate (PHB) was obtained from Sigma Chemicals, India.

\section{Synthesis of SPIONs and drug encapsulated SPIONs}

The synthesis of superparamagnetic iron oxide nanoparticles was carried out by mixing $100 \mathrm{~mL}$ of $1 \mathrm{M} \mathrm{FeCl}_{3} \cdot 6 \mathrm{H}_{2} \mathrm{O}, 1 \mathrm{M} \mathrm{FeSO}_{4} \cdot 7 \mathrm{H}_{2} \mathrm{O}$ and $1 \mathrm{M}$ Cobalt chloride hexahydrate $\left(\mathrm{CoCl}_{2} \cdot 6 \mathrm{H}_{2} \mathrm{O}\right)$ to equal volumes of $5 \mathrm{M}$ Sodium hydroxide solution. The reducing condition for the precipitation method was maintained by heating the precursor solution to $60^{\circ} \mathrm{C}$ for $15 \mathrm{~min}$ while drop wise adding the $\mathrm{CoCl}_{2}-\mathrm{NaOH}$ mixture. Further the contents turned black upon steady exposure while drop wise addition with concentrated ammonia. The precipitates were subsequently washed several times in distilled water to remove excess ammonia and then subjected to lyophilization. $50 \mathrm{mg}$ of the synthesized SPIONs were functionalized by treating it with $25 \mathrm{~mL}$ oleic acid in ethanol for 6-7 h kept in a shaker at room temperature. Particle were made into nanostructure by subjecting to sonication for $45 \mathrm{~min}$ and lyophilized. As mentioned in our earlier studies the drug itraconazole was conjugated to the nano particles and finally encapsulated with polyhydroxybutyrate $(\mathrm{PHB})^{8}$.

\section{Characterization of SPIONs}

The formation of core-shell was carefully monitored and thoroughly characterized by scanning electron microscopy at every stage.

\section{Drug release studies}

The drug release kinetics of SPIONs were done immediately after the encapsulation with PHB by sonication process and lyophilized. The drug release was observed watchfully and

Table 1. In-vitro evaluation of antimicrobial activity of drug encapsulated SPIONs

\begin{tabular}{lccc}
\hline & \multicolumn{3}{c}{ Zone of Inhibition $(\mathrm{cm})$} \\
\cline { 2 - 4 } $\begin{array}{l}\text { Conc. } \\
(\mu \mathrm{g} / \mathrm{ml})\end{array}$ & $\begin{array}{c}\text { Pseudomonas } \\
\text { aeruginosa }\end{array}$ & $\begin{array}{c}\text { Brevibacillus } \\
\text { brevis }\end{array}$ & $\begin{array}{c}\text { Candida } \\
\text { albicans }\end{array}$ \\
\hline $\begin{array}{l}\text { Positive } \\
\text { Control }\end{array}$ & 4 & 3.3 & 2.4 \\
Negative & & & \\
Control & - & - & - \\
5 & 0.8 & - & 0.5 \\
10 & 1.2 & - & 0.7 \\
15 & 1.5 & - & 1 \\
20 & 3.0 & 0.9 & 1.4
\end{tabular}


scrutinized by dialysis methods as detailed in previous reports ${ }^{8,16-18}$ followed with measuring its absorbance at $267 \mathrm{~nm}^{19}$.

\section{In-vitro antimicrobial activity}

The inherent ability of the nanostructures to interact with micro molecules was studied by letting the synthesized SPIONS to intermingle with microorganisms taken in an agar plate. The study was extended to both the bacterial and fungal species namely Pseudomonas aeruginosa, Brevibacillus brevis and Candida albicans ${ }^{2,8}$.

\section{$\mathrm{X}$-ray imaging}

The differential interaction of SPIONs in electromagnetic radiations were observed by exposing them in $\mathrm{X}$ ray which could be developed as material for contrast imaging was carried out by injecting the particle to the yolk of the chicken egg as mentioned in our earlier studies ${ }^{8,19}$.

\section{RESULT AND DISCUSSION Characterization}

The observation of the superparamagnetic iron oxide nanoparticles under Scanning electron microscope at disclosed the change in the size of the nanomaterial as it was processed to core-shell formation. The initial size of the nanoparticle as $20 \mathrm{~nm}$ was subsequently increased to $250 \mathrm{~nm}$ after being functionalized with oleic acid, coated with the drug Itraconazole and encapsulated with poly hydroxy butyrate(Fig. 1a - d). Evidence for the change in size of the particle was reported in earlier researches also ${ }^{8}$.

\section{Drug release studies}

The release profile of the drug Itraconazole by the superparamagnetic iron oxide nanoparticles coated with PHB was observed upto $3 \mathrm{~h}$ (Fig. 2). Extended release profile was likely observed for the PHB based nanoparticle as reported by Senthilkumar et al. ${ }^{18}$. The surface characteristic of the nanomaterial conferring a steady release of the drug molecule encourage the results as to consider the molecule a suitable candidate for sustained release or extended release.
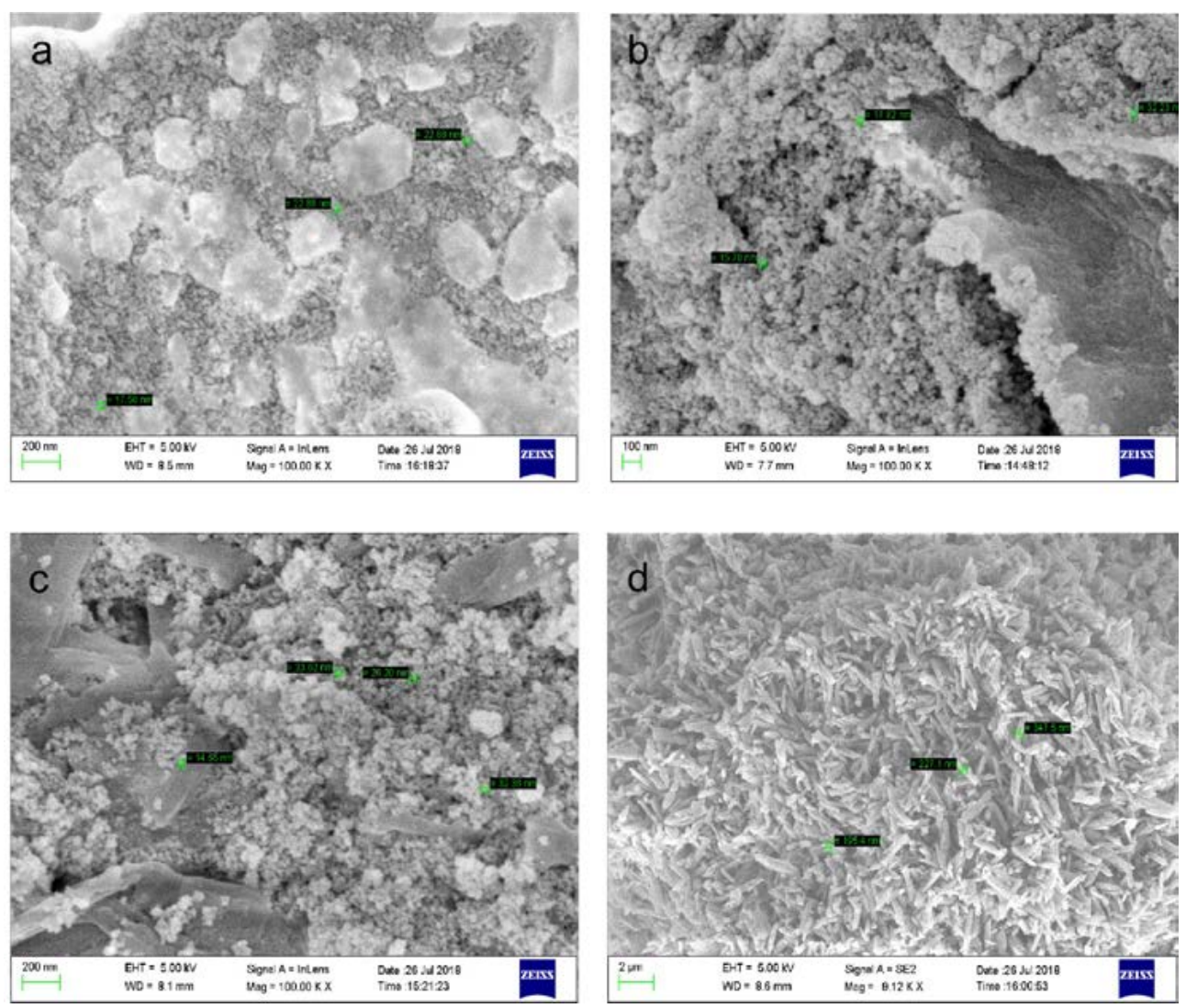

Fig. 1. SEM image a) Naked SPIONs b) Functionalized with oleic acid c) Itraconazole coated d) PHB encapsulated 


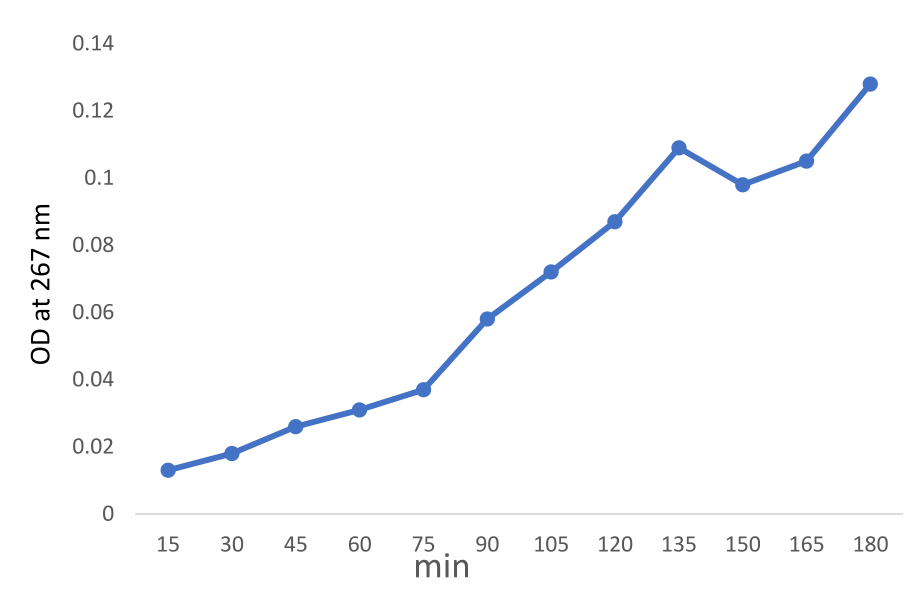

Fig. 2. Drug release pattern of PHB encapsulated coreshell SPIONs
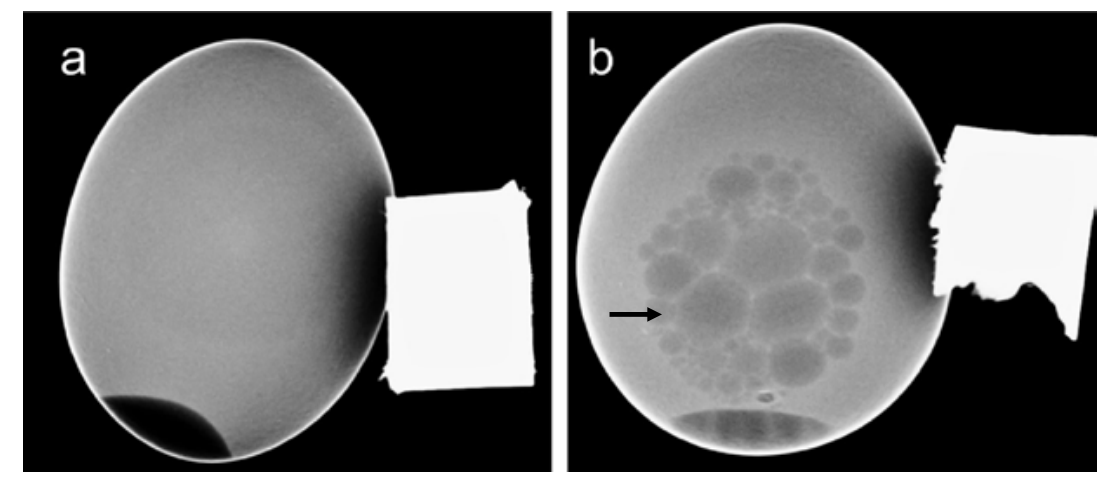

Fig. 3. $X$ ray imaging of SPIONs a) without SPIONs b) with SPIONs. The black arrow denotes the egg yolk (which is clearly seen in SPIONs loaded eggs)

\section{In-vitro antimicrobial activity}

The interaction of the drug loaded superparamagnetic iron oxide nanoparticles on microbial species had pronounced results on both the bacterial and fungal species (Table 1). The almond gum used as a coating agent for the itraconazole loaded nanoparticles too had an effective antibacterial and antifungal response ${ }^{8}$. Extensive studies on these types of nanomolecules with sustained release contours could institute a valuable strategy for treating epidemic outbreaks.

\section{$X$-ray imaging}

SPIONs had differential interaction when observed under $X$ rays. The ability of the molecule to offer a better contrast to the unstained background and illustrating the clear boundary of the yolk as evidenced in(Fig. 3b) than the control (Fig. 3a) could recommend the use of superparamagnetic iron oxide nanoparticles as better contrasting agent in the imaging protocol.
The results coincided with the similar imaging reports of Justin et al ${ }^{20}$ and Sruthi et al. ${ }^{8}$.

\section{CONCLUSION}

The superparamagnetic iron oxide nanoparticles (SPIONs) synthesized by coprecipitation method in presence of cobalt was found to be around $20 \mathrm{~nm}$ in size. These molecules upon funtionalization, drug loading and encapsulation were increased in size to 250 $\mathrm{nm}$. The SPIONs was noticed to have a constant, extended drug release profile following first order kinetics and releasing drug steadily and successful in combating the microbial growth. Further this molecule also proffered as a contrasting agent under $\mathrm{X}$ rays. It is amazing that these molecules can be proposed to target microbes admonishing a suitable choice for sustained drug candidate. These materials in nanoscale could offer promising results to combat bacteria and fungi. Further their 
proficient imaging profile as a contrasting agent could suggest an effective approach to track the microbial colonization and targeted drug delivery.

\section{ACKNOWLEDGMENTS}

None.

\section{CONFLICT OF INTEREST}

The authors declare that there is no conflict of interest.

\section{FUNDING}

None.

\section{AUTHORS' CONTRIBUTION}

The ideology and research were supported by all the authors. All the authors involved in manuscript writing.

\section{ETHICS STATEMENT}

This article does not contain any studies with human participants or animals performed by any of the authors.

\section{DATA AVAILABILITY}

All datasets generated or analyzed during this study are included in the manuscript.

\section{REFERENCES}

1. Raji P, Samrot, AV, Bhavya KS, Sharan M, Priya S, Paulraj, P. Greener Approach for Leather Tanning Using Less Chrome with Plant Tannins and Tannins Mediated Nanoparticles. J Clust Sci. 2019. https://doi. org/10.1007/s10876-019-01597-6

2. Samrot AV, SenthilKumar P, Rashmitha S, Veera P, Sahithya CS. Azadirachtaindica influenced biosynthesis of superparamagnetic iron oxide nanoparticles and their applications in tannery water treatment and $\mathrm{x}$-ray imaging. Nanostructure in Chemistry. https:// doi.org/10.1007/s40097-018-0279-0

3. Samrot AV, Shobana N, Kumar SS, Narendrakumar G. Production, optimization and characterisation of chitosanase of bacillus sp and its applications in nanotechnology. Journal of Cluster Science. 2019;30(3):607-620. https://doi.org/10.1007/s10876019-01520-z

4. Raji P, Samrot AV, Keerthana D, Karishma S. Antibacterial Activity of Alkaloids, Flavonoids, Saponins and Tannins Mediated Green Synthesised Silver Nanoparticles Against Pseudomonas aeruginosa and Bacillus subtilis. Journal of Cluster Science. 2019: https://doi. org/10.1007/s10876-019-01547-2

5. Samrot AV, Shobana N, Sruthi DP, Sahithya CS. Utilization of chitosan coated superparamagnetic iron oxide nanoparticles for chromium removal. Applied Water Science. 2018;8:192. https://doi.org/10.1007/ s13201-018-0841-4

6. Samrot AV, Raji P, Selvarani AJ, Nishanthini P. Antibacterial activity of some edible fruits and its green synthesized silver nanoparticles against uropathogen - Pseudomonas aeruginosa SU 18. Biocatal Agric Biotechnol. 2018;16:253-270. https:// doi.org/10.1016/j.bcab.2018.08.014

7. Samrot AV, Silky Ignatious CV, Raji P, SaiPriya C, Selvarani JA. Bioactivity Studies of Datura metel, Aegle marmelos, Annona reticulata and Saracaindica and their Green Synthesized Silver Nanoparticle. J Pure Appl Microbiol. 2019;13(1). https://doi.org/10.22207/ JPAM.13.1.36

8. Sruthi PD, Sahithya CS, Justin C, et al. Utilization of Chemically Synthesized Super Paramagnetic Iron Oxide Nanoparticles in Drug Delivery, Imaging and Heavy Metal Removal. Journal of Cluster Science. 2018. https://doi.org/10.1007/s10876-018-1454-7

9. Mahmoudi M, Sant S, Wang Laurent S, Sen T. Superparamagnetic iron oxide nanoparticles (SPIONs): Development, surface modification and applications in chemotherapy. Advanced Drug Delivery Reviews. 2011;63(1-2):24-46. https://doi.org/10.1016/j. addr.2010.05.006

10. Justin C, Samrot AV, Annamalai A, Bhattacharya R, Sathiyamoorthy P, Sahithya CS. Biopolymer coated coreshell magnetite nanoparticles for rifampicin delivery. Orient J Chem. 2018;34(5). https://doi. org/10.13005/ojc/340521

11. Justin C, Samrot AV, Sruthi PD, Sahithya CS, Bhavya KS, Saipriya C. Preparation, characterization and utilization of coreshell super paramagnetic iron oxide nanoparticles for curcumin delivery. PLos One. 2018;13(7):e0200440. https://doi.org/10.1371/ journal.pone.0200440

12. Kodama RH. Magnetic nanoparticles, Journal of Magnetism and Magnetic Materials. 1999;200(13):359-372. https://doi.org/10.1016/S03048853(99)00347-9

13. Senyei A, Widder K, Czerlinski G. Magnetic guidance of drug-carrying microspheres. Journal of Applied Physics. 1978;49(6):3578-3583. https://doi. org/10.1063/1.325219

14. Alexiou C, Arnold W, Klein RJ, et al. Locoregional cancer treatment with magnetic drug targeting, Cancer Research. 2000;60(23):6641-6648.

15. Samrot AV, Sahithya CS, Selvarani AJ, Pachiyappan S, Kumar SS. Surface-Engineered Super-Paramagnetic Iron Oxide Nanoparticles for Chromium Removal. International Journal of Nano Medicine. 2019;81058119. https://doi.org/10.2147/IJN.S214236

16. Samrot AV, Akanksha Jahnavi T, Padmanaban S, Philip SA, Burman U, Rabel AM. Chelators influenced synthesis of chitosan-carboxymethyl cellulose microparticles for controlled drug delivery. Applied Nanoscience. 2016;6:1219-1231. https://doi. org/10.1007/s13204-016-0536-9

17. Samrot AV, Burman U, Philip SA, Shobana N, Chandrasekaran K. Synthesis of curcumin 
loaded polymeric nanoparticles from crab shell derived chitosan for drug delivery. Informatics in Medicine Unlocked. 2018;10:159-182. https://doi. org/10.1016/j.imu.2017.12.010

18. Senthilkumar P, Dawn SS, Samanvitha SK, Saipriya C, Samrot AV. Surfactant Mediated Synthesis of Polyhydroxybutyrate (PHB) Nanoparticles for Sustained Drug Delivery. IET Nanobiotechnology. 2019.

19. Samrot AV, Bhavya KS, Sruthi P, Raji P, Ponnaiah P.
Synthesis of SPIONs to deliver drug in-vitro and to use as contrasting agent. International Journal of Advanced Research in Engineering and Technology (IJARET). 2020;11(2):200-208.

20. Justin C, Philip SA, Samrot AV. Synthesis and characterization of superparamagnetic iron-oxide nanoparticles (SPIONs) and utilization of SPIONs in X-ray imaging. App/ Nanosci. https://doi.org/10.1007/ s13204-017-0583-x 